DOI : 10.31357/fapsmph.1997.00613

A study of fish fauna of ornamental value with special reference to Danto malabaricus in two main tributaries (Wak Oya and Pusweli Oya) of the Kelani River.

Weerawanni Mudiyanselage Chandrika Indunil Divigalpitiya

Thesis submitted to the University of Sri Jayewardenepura for the award of the degree of Master of Philosophy in Zoology.

M.Phil. 


\section{Memorandum}

The work described in this thesis was carried out by me at the Department of Zoology, University of Sri Jayewardenepura, Nugegoda, Srt Lanka, under the supervision of Dr. (Mrs) Afantha De Alwis and Professor. J.Jinadasa, and the report on this has not been submitted to any university for another degree.

Date: $98 \cdot 10 \cdot 20$

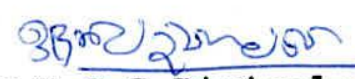

w.M.C.I.Divigalpitiya. 
We certify that the above statement made by the candidate is true and that this thesis is suitable for submission to the university for the purpose of evaluation.

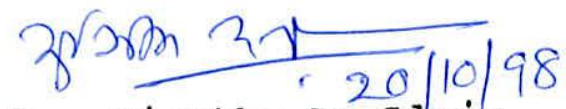

Dr. Ajantha De Alwis

Supervisor

Senior Lecturer,

Department of zoology

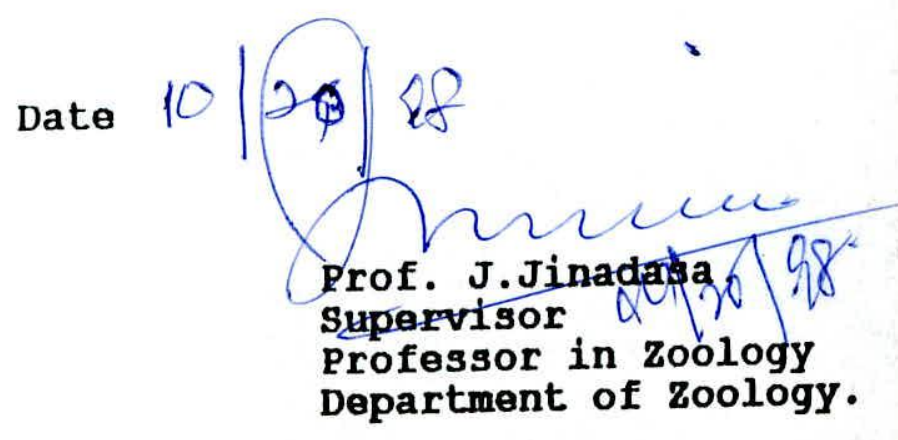




\section{Memorandom}

Table of Contents $\ldots \ldots \ldots \ldots \ldots \ldots \ldots \ldots \ldots \ldots \ldots \ldots \ldots \ldots$

List of Tables......................... VI

List of Figures....................... VIII

Acknowledgments........................ XI

Abstract...............................

Chapter 1. Introduotion $\ldots \ldots \ldots \ldots \ldots \ldots \ldots \ldots \ldots \ldots, 1$

Chapter 2. Materials and methods...............9

2.1 The study area...................... 9

2.2 study period........................ 10

2.3 Sampling stations................... 10

2.4 Frequency of Sampling................. 11

2.5 Biological parameters.................. 11

2.5.1 Fish and plankton samples............... 11

2.5.2 Morphological features of species.......... 12

2.5 .3 Feeding ecology $\ldots \ldots \ldots \ldots \ldots \ldots \ldots \ldots \ldots \ldots \ldots \ldots \ldots$

2.6 Population studies.................. 16

2.6 .1 Species abundance..................... 16

2.6.2 Distribution of D.malabaricus............ 17

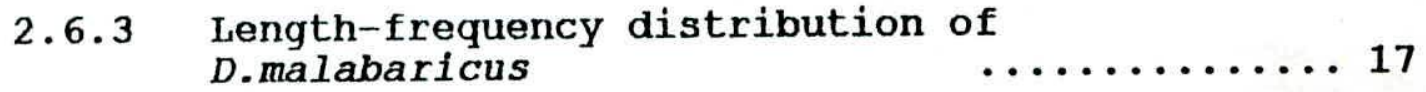

2.6.4 Length - weight relationship of D.malabaricus 
2.7 Reproductive Biology of D.malabaricus........20

2.7 .1 Sex ratio of $D$. malabaricus $\ldots \ldots \ldots \ldots \ldots \ldots \ldots \ldots 20$

2.7 .2 Gonadosomatic index of D.malabaricus......... 20

2.7.3 Development of Ova of D.malabaricus......... 21

2.7 .4 Fecundity of D.malabaricus............... 22

2.8 Sampling for resources partitiong...........23

2.9 other physical and chemical parameters .......24

2.10 Exploitation of fish for ornamental purposes and food $\quad \ldots \ldots \ldots \ldots \ldots 25$

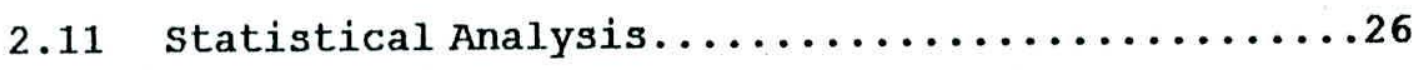

\section{CHAPTER 3. Results}

3.1 General species composition of the freshwater fish fauna $\quad \ldots \ldots \ldots \ldots 27$

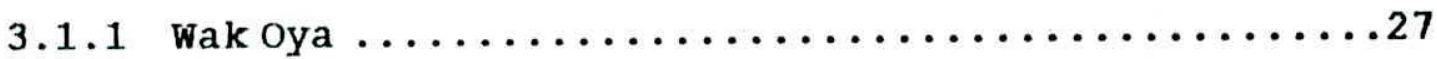

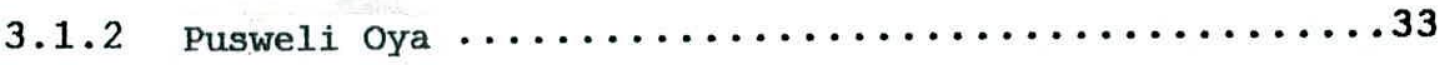

3.2 Longitudinal distribution of ornamental fish.... 34

3.2.1 Longitudinal distribution of ornamental fish

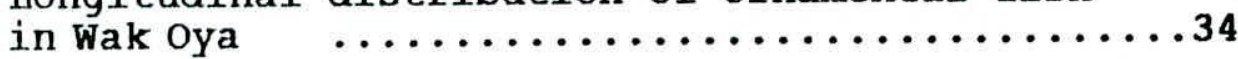

3.2.2 Ionqitudinal distribution of ornamental fish

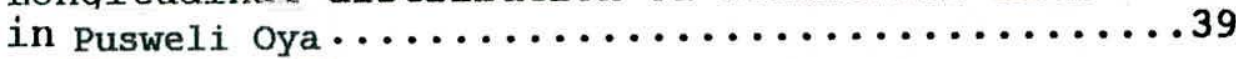

3.3 Monthly variation of the species composition.....42

3.3.1 Monthly variation of the number of ornamental fish inwakoya.....................42

3.3.2 Monthly variation of the number of ornamental fish in Pusweli oya ..................46 
3.4 Species diversity indices (Shannon diversity

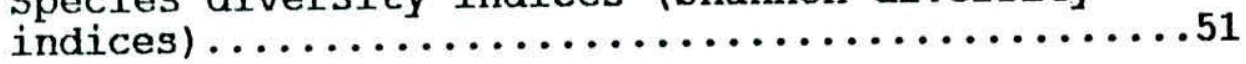

3.5 Relationship of chemical parameters with the abundance of ornamentally important fish species

3.5.1 Relationship of mean chemical parameters and mean fish abundance in stations at wak Oya for the total study period................. 52

3.5.2 Relationship of mean monthly values and chemical parameters and the mean monthly values of abundance of ornamental fish in WakOya .

3.5.3 Relationship of mean chemical parameters and mean fish abundance in stations at Pusweli Oya for the total study period.................... 58

3.5.4 Relationship of mean monthly values and chemical parameters and the mean monthly values of abundance of ornamental fish in

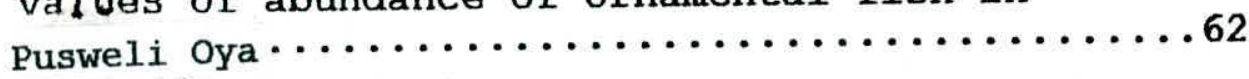

3.5.5 Resuls of pesticides residuce.............64

3.6 Relationship between fish abundance and

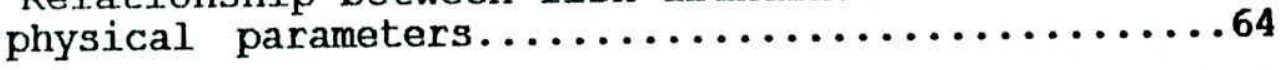

3.6 .1 water temperature.....................64

3.6.2 Rainfall and flow velocity...............6 67

3.7. Resource partitioning of fish in the streams $\ldots .67$

3.7.1 partitioning of food.......................

3.7.2 Morphological features responsible in Resource partitioning.................... 75 
3.7.3 Partitioning of habitats................. 78

3.8 Exploitation of fish species in two streams......82

3.9 Some biological aspects of $D$. malabarlcus.........84

3.9 .1 Distribution of $D$. malabaricus $\ldots \ldots \ldots \ldots \ldots \ldots . \ldots 8$

3.9.1.1 Distribution of D.malabaricus in the two streams for the total study period ..........84

3.9.1.2 Monthly Distribution of D.malabaricus in the two streams for the total study period ..........89

3.9.2 Population Dynamics..................... 89

3.9.2.1 Length frequency of $D$.malabar1cus.............89

3.9.2.2 Length-weight relationship of D.malabaricus......96

3.9.3 Feeding ecology of of D.malabaricus............100

3.9.3.1 General food composition of D.malabaricus.......100

3.9.3.2 Percentage contribution of food of males and

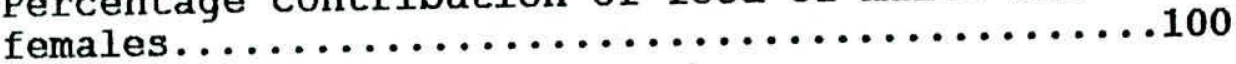

3.9.3.3 Percentage contribution of food items of the diet of various size groups of D.malabaricus.....100

3.9.3.4 Relationship between the occurrence and preference of the diet of D.malabaricus . . . . . . 104

3.9.4 Reproductive Biology of D.malabarlcus........... 104

3.9.4.1 Sex ratio of D.malabaricus................104

3.9.4.2 Minimum size at first maturity of D.malabaricus..108

3.9.4.3 Gonado-somatic index (GSI) of D.malabaricus.....108

3.9.4.4 Development of ova ..................111

3.9.4.5 Fecundity of D.malabaricus..............111 


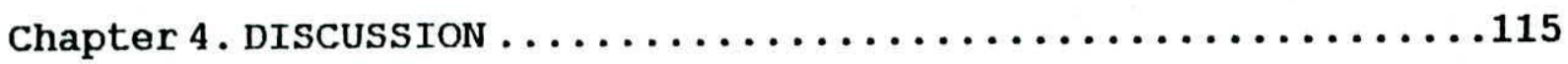

* Occurrence and distribution of fish in the two streams.................................

* Factors influencing the distribution and occurence of the fish........................117

* Partitioning of resources....................117

${ }^{\star}$ Environmentalfactors.........................

${ }^{\star}$ Habitat modification....................... 125

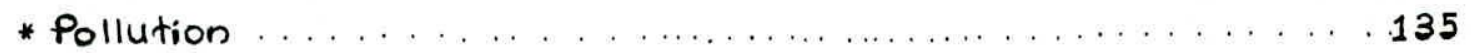

* Population study of D.malabaricus...............138

* Age and growth of D.malabaricus.................... 159

* Length-weight of $D$.malabaricus.................. 140

* Feeding ecology of D.malabaricus................. 140

* Reproductive biology of D.malabaricus .............142

Referenoes.................................

Appendix I...................................

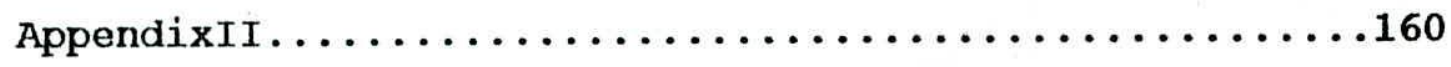

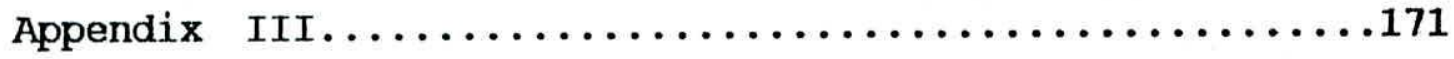

Appendix IV...............................

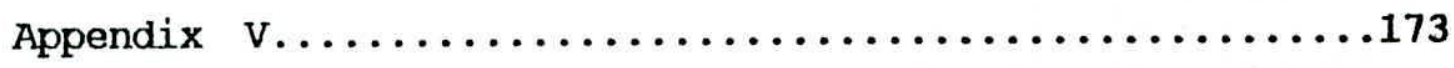


Ligt of tables

Table I The species composition of $f$ ish in the

streams and their status.........................29

Table II Ornamental fish density $\left(\mathrm{No} / \mathrm{m}^{2}\right)$ of Wak Oya

in $92 / 93$ period............................... 44

Table III Ornamental figh density $\left(\mathrm{No} / \mathrm{m}^{2}\right)$ of Wak Oya

in $93 / 94$ period.............................. 45

Table IV Ornamental fish density $\left(\mathrm{No} / \mathrm{m}^{2}\right)$ of Pusweli Oya

in $92 / 93$ period.............................. 48

Table $V$ Ornamental fish density $\left(\mathrm{No} / \mathrm{m}^{2}\right)$ of Pusweli Oya

in $93 / 94$ period..............................49

Table VI Species diversity and species evenness of fish

in two streams................................. 50

Table VII Mean chemical and physical composition in

different stations of Wak Oya for the total

study period (pooled data for the year $92 / 92$ and 93/94) ...53

Table VIII Mean chemical and physical composition in

different stations of Pusweli Oya for the total

study period(pooled data for the year $92 / 92$ and $93 / 94) \ldots 54$

Table IX Mean monthly chemical and physical composition

of Wak Oya for the total study period(pooled data for

the year $92 / 92$ and $93 / 94) \ldots \ldots \ldots \ldots . \ldots \ldots$

Table $X \quad$ Mean monthly chemical and physical composition of

Pusweli Oya for the total study period (pooled data for

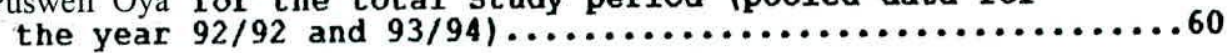

Table XI Mean values of morphological characteristics of

selected ornamental fish in the study area...............76

Table XII Habitat characteristics of gelected ornamental

fish in the study area............................

Table XIII Percentage composition of the diet of ornamental

fish species in the study area (pooled data for

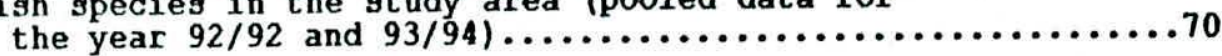

Table XIV The Electivity index of selected ornamental fish

in the study area (pooled data of the two streams

during the total study period) $\ldots \ldots \ldots \ldots \ldots \ldots \ldots \ldots \ldots \ldots \ldots$

Table XV The Schoener's index of selected ornamental fish

in the study area (pooled data of the two streams

during the total study period) $\ldots \ldots \ldots \ldots \ldots \ldots \ldots \ldots \ldots \ldots \ldots \ldots \ldots 74$ 
Table XVI Data on collection of fish for ornamental

and/or food purposes from the two streams for

the total study period................................

Table XVII Duncan's grouping for the distribution

of $D$. malabaricus in Wak Oya in different

stations (pooled data of $92 / 93$ and 93/94)

for the total study period and for the

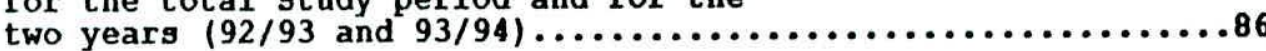

Table XVIII Duncan's grouping for the distribution of $D$. malabaricus in Pusali oya in different

stations (pooled data of $92 / 93$ and 93/94)

for the total study period and for the

two years $(92 / 93$ and $93 / 94) \ldots \ldots \ldots \ldots \ldots \ldots \ldots \ldots \ldots \ldots \ldots . \ldots . \ldots . \ldots$

Table XIX Growth parameters, mortality rates, exploitation

rate and size at first capture of $D$. malabaricus

in the study area.................................92

Table XX Schoener's indices for different size classes of D. malabaricus (pooled data of the two streams

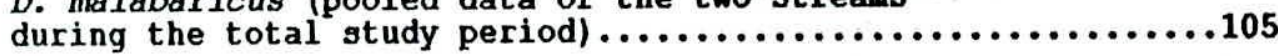

Table XXI Sex ratio of D. malabaricus (pooled data of the two streams during the total study period) ............ 106 


\section{Ilst of Figures}

Fig.1 Map of the study area (All Sampling stations are marked as st and sites in the two reservoirs are marked as R)

Fig.2 Percentaqe composition of major fish families in Wak Oya and Pusweli Oya for the total study period (pooled data of

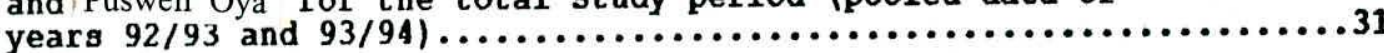

Fig. 3 Species abundance (given as total number of fish observed) of ornamental figh in Wak Oya for the total study period

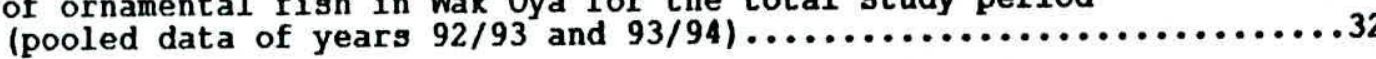

Fig. 4 Species abundance (qiven as total number of fish observei) ornamental fish in Pusweli Oya for the total study period

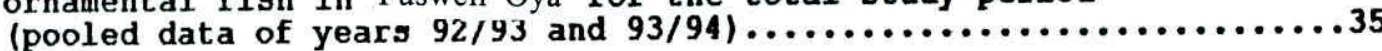

Fig. 5 Longitudinal distribution (Total number of fish of each species in different stations) of ornamental fish

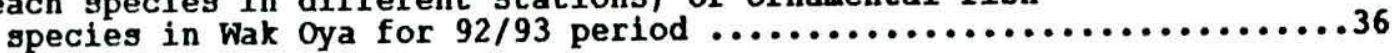

Fig. 6 Longitudinal distribution (Total number of fish of each species in different stations) of ornamental fish species in Wak Oya for $93 / 94$ period.............................

Fig. 7 Longitudinal distribution (Total number of fish of each species in different stations) of ornanental figh species in Pusweli Oya for $92 / 93$ period $\ldots \ldots \ldots \ldots \ldots \ldots \ldots \ldots \ldots \ldots . \ldots 40$

Fig. 8 Longitudinal distribution (Total number of fish of each species in different stations) of ornamental fish species in Pusweli Oýa for $93 / 94$ period....................41

Fig. 9 Monthly variation of the mean abundance (given as mean number) of ornamental fish in Wak Oya for the total study period (pooled data of years $92 / 93$

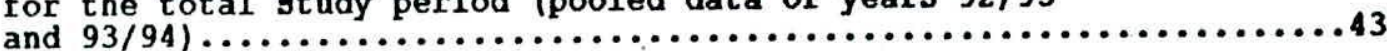

Fig.10 Monthly variation of the mean abundance (given as mean number) of ornamental fish in Pusweli Oya for the total study period (pooled data of years $92 / 93$ and $93 / 941$.

Fig.11 Relationship of mean chemical parameters and mean abundance (given as mean number) of ornamental fish in different sampling stations of Wak Oya for the total study period (pooled data of years $92 / 93$ and 93/94)

Fig.12 Relationship of monthly mean chemical parameters and monthly mean abundance (given as mean number) of ornamental fish in different sampling stations of Wak Oya for the total study period (pooled data of years $92 / 93$ and $93 / 94$ ) 
Fig.13 Relationship of mean chemical parameters and mean abundance (given as mean number) of ornamental fish in different sampling stations of Pusweli Oyal for the total study period

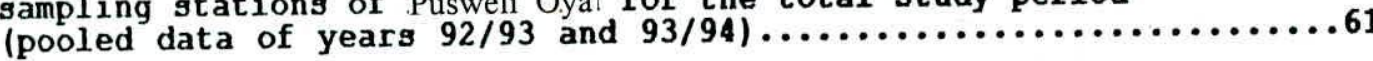

Fig.14 Relationship of monthly mean chemical parameters and monthly mean abundance (given as mean number) of ornamental figh in different sampling stations of Pusweli Oya for the total study period (pooled data

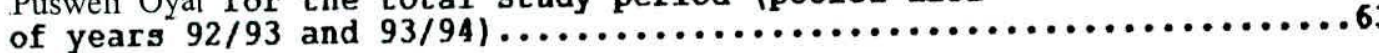

Fig.15 Relationship of mean water temperature and mean abundance (given as total mean number) of ornamental fish in different sampling stations of Wak Oya for the total study

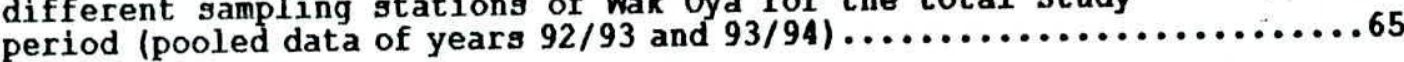

Fig.16 Relationship of monthly mean water temperature, mean flow velocity, mean rainfall and mean fish abundance (given as mean number) of ornamental fish in Wak Oya for the total study period (pooled data of years $92 / 93$ and 93/94) 68

Fig.17 Relationship of mean water temperature and mean abundance (given as total mean number) of ornamental fish in different sampling stations of Pusweli Oya for the total study period (pooled data of years $92 / 93$ and 93/94) ..........66

Fig.18 Relationship of monthly mean water temperature, mean fl velocity, mean rainfall and mean fish abundance (given as mean number) of ornamental fish in Pusweli Oya for the total study period (pooled data of years $92 / 93$ and $93 / 94$ ) ...........69

Fig.19 Morphological key of the selected ornamental fish species

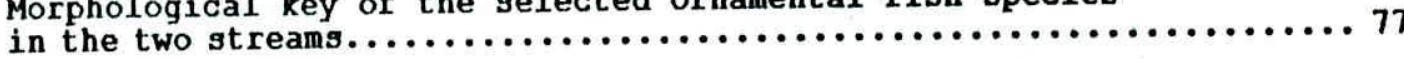

Fig.20 Ecological key of the selected ornamental fish species in

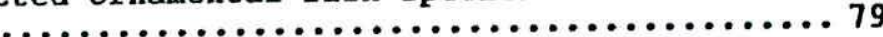

Fig.21 Mean density $\left(\mathrm{No} / \mathrm{m}^{2}\right)$ of D.malabaricus in Wak Oya for

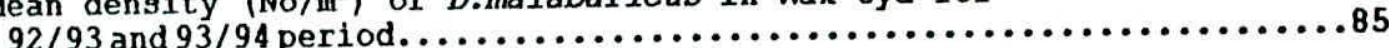

Fig. 22 Mean density $\left(\mathrm{No} / \mathrm{m}^{2}\right)$ of D.malabaricus in Pusweli Oya for

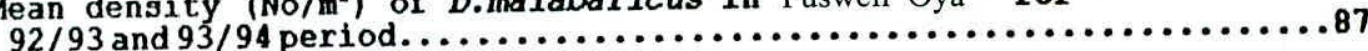

Fig. 23 Monthly variation of mean density (No/m") of D.malabaricus in Wak Oya for $92 / 93$ and $93 / 94$ period............................. 90

Fig. 24 Monthly variation of mean density $\left(\mathrm{No} / \mathrm{m}^{*}\right)$ of D.malabaricus in Pusweli Oya for $92 / 93$ and $93 / 94$ period......................... 
Fig. 25 Growth curves (solid curve) of D. malabaricus, superimposed on the length-frequency distribution. The curve of broken lines indicates a growth curve of same growth parameters representing another peak recruitment.........................................93

Fig. 26 A.Length-converted catch curve for D. malabaricus, in the study area. B. Selection curve of $D$. malabaricus,

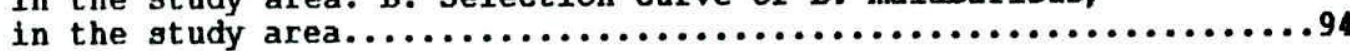

Fig. 27 Recruitment pattern of $D$. malabaricus in the study area.........95

Fig. 28 Relationship of length and weight of male and female D. malabaricus (Pooled data of the two streams during the total study period) .........................

Fig. 29 Logarithmic length-weight relationship of male and female $D$. malabaricus (Pooled data of the two streans during the total study period) $\ldots \ldots \ldots \ldots \ldots \ldots \ldots \ldots \ldots \ldots \ldots \ldots . \ldots . \ldots 9 . \ldots \ldots$

Fig. 30 General food composition of D. malabaricus (Pooled data of all size classes of the two streams during the total

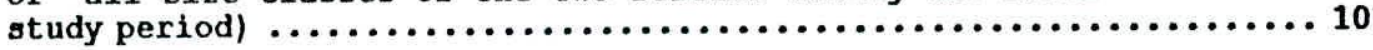

Fig. 31 Percentage composition of various food items in male and female $D$. malabaricus (Pooled data of the two streams

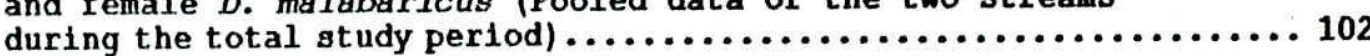

Fig. 32 Percentage composition of various food items in different size clasges of $D$. malabaricus (Pooled data of the two streams during the total study period) $\ldots \ldots \ldots \ldots \ldots \ldots 103$

Fig. 33 Monthly percentage distribution of mature and immature females of $D$. malabaricus (Pooled data of the female $D$. malabaricus of the two streams

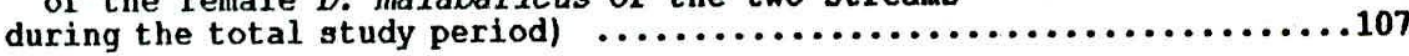

Fig. 34 Percentage distribution of mature and immature males and females in different size clases of $D$. malabaxicus (Pooled data of the two streams during the total study period)

Fig. 35 Seasonal variation of GSI of female D. malabaricus (Pooled data of the two streams during the total study period)

Fig. 36 ova diameter frequency polygons for various stages of maturity in $D$. malabaricus (Pooled data of the two streams

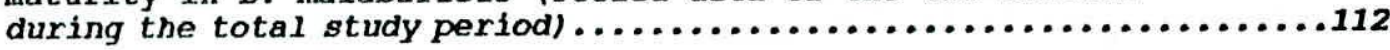

Fig. 37 Relationships between fecundity and the standard length, total weight and ovary weight of $D$. malabaricus (Pooled data of the two streams during the total study period) 


\section{Acknowledgments}

First and foremost I wish to express my sincere gratitude to my supervisors, Dr. Ajantha De Alwis, senior lecturer and Prof. J. Jinadasa, Head, Department of Zoology, of the University of sri Jayewardenepura for their relentless guidance and inestimable courage given to me to continue the project. I have to thank especially to Dr. Ajantha De Alwis for her unlimited devotion and encouragement during the course of study. An expression of gratitude is also due to Mr. P. Dias, Lecturer, Department of Mathematics and Mrs. Darshini Mahaulpotha, Lecturer, Department of Zoology for assisting me in statistical analysis.

I also wish to extend my gratitude to Prof. U.S. Amarasinghe, of the Department of zoology, of the university of Kelaniya analysis of fish who helped men with length-frequency data.

I would like to thank Mr. A.B. Kotalawala, museum curator, Department of zoology, for giving me help in various ways.

I should not miss thanking the work supervisors and the staff of Labugama and Kalatuwawa reservoirs for their willing cooperation throughout the sampling.

My gratitude goes to Mr.K.S. Wijenayake, Technician, Department of Zoology and Miss D.Geewandarage, Demonstrator, Department of zoology for helping me in photography and drawing diagrams.

I also like to express my thahk to Miss Deepani senevirathna, Lecturer, Department of Zoology for her sincere assistance in preparing the thesis. I must also thankfully remember the staff 
of the Computer Centre of University of Sri Jayewardenepura, for their kind assistance in computer programming and printing. I would like to say a big 'thank you' the members of my family, especially my mother, father and my husband Athula for their ready understanding and constant encouragement which made my work a complete achievement.

I also wish to place on record of my gratitude to all staff of Department of zoology, University of sri Jayewardenepura, too numerous to individually mention, who helped me in various ways to make this a success.

I must also thankfully remember Mr. Dhammika Perera for the trouble taken to print out the final copy of this thesis. Finally, I must mention that this research was carried out as a

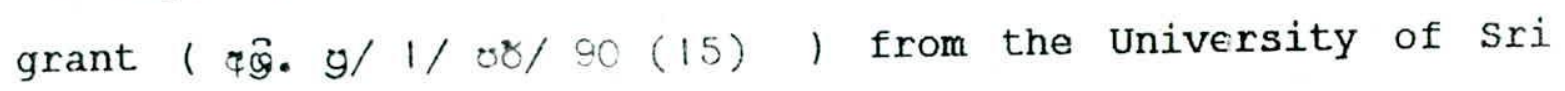
Jayewardenepura, Nugegoda, sri Lanka for which I am very grateful. 
A study of fish fauna of ornamental value, with special reference to Danio malabaricus in two main tributaries (Wak oya and Pusweli Oyal) of the Kelani River

\title{
W.M.C.I. DIVIGALPITIYA
}

September 1997

\begin{abstract}
Fish assembalge in two tributaries of Kelani river, namely, Wak Oya stream and Pusweli Oya stream situated in the southwestern Ichthyological province of Sri Lanka was studied for a period of twenty five months from 01 ${ }^{\text {st }}$ March 1992- $31^{\text {st }}$ March 1994.
\end{abstract}

These two streams are inhabited by thirty species of fish, out of which five are endemic and ninteen are indigenous. Twenyty five of the thirty species (including the five endemic species) recorded are of ornamental value, either exported to be used in aquaria or used locally in aquaria. The ornamental fish assemblage stuided is highly structured as reflected in their morphological differences and habitat segregation which enhance the co-existence of such a variety of species. However, they show a considerable qualitative food overlap but their quantitative food selection help them to coexist. This type of high degree of specialization reveals the fact that, the fish assemblage under study is maintaining an equilibrium and their co-existence is a cumulative result of morphological, habitat and trophic specializations. Therefore, a slight change caused by any adverse effect in this community can bring detrimental results to the whole system. 
Differences can be seen in the distribution and occurrence of ornamentally important fish in these two streams which could be attributed to some of the environmental factors studied. They are chemical and physical factors such, as dissolved oxygen, conductivity, total hardness, total alkalinity and flow velocity of water in the streams, gem/sand mining, deforestation and construction of weirs in the streams. Direct factory discharges and pesticides and insecticides which are added to the streams directly (ie. cleaning of gear used for spraying) also seems affecting the fish. These observations emphasizes the fact that there are many factors operating in these two streams that affect the delicate balance of the fish assemblage and timely attention has to be paid in implementing a rational management of these two systems.

Some biological aspects of the most abundant ornamental fish species, Danio malabaricus were studied. The Length frequency data obtained from the commercial fish collectors in the study area were analysed using compleat ELEFAN software. The asymptotic total length $\left(\mathrm{L}_{\mathrm{cs}}\right)$ is $70.5 \mathrm{~mm}$, von Bertalanfy growth coefficient $(K)$ is 1.2 year $^{-1}$ and theoritical age at length zero $\left(t_{0}\right)$ is -0.2 years. The Growth performance index ( $\left.\varnothing^{\prime}\right)$ of this species is 3.78 . The total mortality (Z), natural mortality (M) and fishing mortality (F) are estimated to be 5.81 year $^{-1}, 3.01$ year $^{-1}$ and 2,80 year ${ }^{-1}$ respectively. The exploitation rate $(E)$ is 0.48 indicating that the stock is not over-exploited but it 
also indicates that the natural mortality (M) of this species is higher than the fishing mortality (F). This emphasizes the point that, an increase in the fishing mortality on this species, in which the natural mortality is already high can be very harmful. The annual recruitment of this species occurs as two recruitment pulses separated by a 4-5 months interval. The mean size at first capture of this species is $39.36 \mathrm{~mm}$.

Both sexes of the fish show a typical length-weight relationship, weight increasing with length, rapidly at the beginning and then slowing down. There is no significant difference between the length-weight relationship of males and females. The exponent $\mathrm{b}$ is 2.7 for male and 2.8 for female, indicating that this species shows an allometric growth.

Studies of feeding of D.malabaricus show that this species is an omnivore, feeding primarily on insects (Both terrestrial and aquatic) and crustaceans. There is a high positive selection of insect larvae, insects, cladocerance such as Ceriodaphnia,Bosmina and Daphnia. A qualitative difference in food items between the males and females is also shown, which may be due to some ecological segregation of sexes in the habitat they occupy. There is a high qualitative food overlap among the size classes with a quantitative difference in prey size, where smaller size classes consume smaller prey items while large classes consume large prey items. This may be attributed to the morphological differences (ie. size of the 
mouth) in the size classes.

The sex ratio of this species is $1: 1.4$ (male :female) showing that the females predominate the population. Such difference could be due to a partial segregation of mature forms through habitat preference or due to migration or behavioural differences between sexes or a cumulative result of one or more of the above. The minimum size at first maturity is $48 \mathrm{~mm}$ for females and $52 \mathrm{~mm}$ for males indicating that the females attain maturity earlier than the males. The reason for this could be the size differences between males and females where females of this species were generally larger than the males. Females reach full maturity (100\%) at $65.1 \mathrm{~mm}$ and males at $70 \mathrm{~mm}$.

D. malabaricus,is a multiple spawner, spawning from April to September with a peak spawning In April and September. Mature eggs of the species show a minimum diameter of $0.1 \mathrm{~mm}$ and the range can vary from $0.1-0.14 \mathrm{~mm}$. The fecundity of female is 458 (SD \pm 165 ) and fecundity is best related with weight of ovaries and tha total weight of fish. 